\title{
Risk factors for fatality in HIV-infected patients with NRTI-induced severe hyperlactataemia or lactic acidosis
}

Alejandro Arenas-Pinto ${ }^{1,2}$, Alison Grant ${ }^{3}$, Krishnan Bhaskaran ${ }^{4}$, Andrew Copas ${ }^{1}$, Andrew Carr 5 , Signe W Worm ${ }^{6}$, Esteban Martinez ${ }^{7}$, Peter Reiss ${ }^{8}$, David Dunn ${ }^{9}$, Rainer Weber ${ }^{10}$, Jennifer Hoy ${ }^{11}$ and lan Weller ${ }^{1}$ on behalf of the Lactic Acidosis International Study Group.

${ }^{1}$ Centre for Sexual Health \& HIV Research, University College London; ${ }^{2}$ Faculty of Medicine, Universidad Central de Venezuela; ${ }^{3}$ Clinical Research Unit and ${ }^{4}$ Non-Communicable Diseases Epidemiology Unit, London School of Hygiene \& Tropical Medicine; ${ }^{5}$ St Vincent's Hospital, Sydney, Australia; ${ }^{6}$ Copenhagen HIV Programme, University of Copenhagen, Denmark; ${ }^{7}$ Hospital Clinic, Barcelona, Spain; ${ }^{8}$ Academic Medical Center, University of Amsterdam, Amsterdam, The Netherlands; ${ }^{9}$ Clinical Trials Unit, Medical Research Council, London, UK; 10University Hospital, Zurich, Switzerland; ${ }^{11}$ Alfred Hospital, Monash University Melbourne, Australia.

Key words: HIV, NRTI, lactic acidosis, hyperlactataemia, mortality

Running head: Fatality in NRTI-induced lactic acidosis

Corresponding author: Dr Alejandro Arenas-Pinto, Centre for Sexual Health \& HIV Research, The Mortimer Market Centre, off Capper Street, London WC1E6JB, UK

E-mail: AArenas-Pinto@gum.ucl.ac.uk; Phone number: +44 (0)8451555000 Ext. 8660; Fax number: $+44(0) 2073809687$.

\section{Word count:}

- Abstract: 249 words

- Text: 3,141 words

\begin{abstract}
Background: Lactic acidosis (LA) and severe hyperlactataemia (HL) are infrequent but serious complications of antiretroviral therapy which have been associated with a high fatality rate.

Methods: In a multinational retrospective cohort study LA was defined as arterial blood $\mathrm{pH}<7.35$, bicarbonate $<20 \mathrm{mmol} / \mathrm{l}$ and lactate above normal and $\mathrm{HL}$ as confirmed blood lactate $>5 \mathrm{mmol} / \mathrm{l}$. Logistic regression was used to identify factors associated with fatality. Sensitivity and specificity of different case definitions as predictor of death were compared.

Results: The overall case-fatality rate was $19 / 110$ (17.3\%) but among acidotic patients it was $33 \%$ (16/49 cases). There were 10 asymptomatic patients and none of them died as consequence of the event. The median lactate for fatal, non-fatal and all patients was $8.3 \mathrm{mmol} / \mathrm{I}$ (IQR=7.2-13.1), $6.4 \mathrm{mmol} / \mathrm{l}(\mathrm{IQR}=5.4-7.8)$ and $6.7 \mathrm{mmol} / \mathrm{l} \quad(\mathrm{IQR}=5.5-8.1)$ respectively. After adjusting for age and current CD4 cell count, lactate $>7 \mathrm{mmol} / \mathrm{l}$ $(\mathrm{OR}=6.27 ; 95 \% \mathrm{Cl}=1.13-34.93)$, blood bicarbonate $<12 \mathrm{mmol} / \mathrm{l}(\mathrm{OR}=10.02$ relative to $>18$ $\mathrm{mmol} / \mathrm{l} ; 95 \% \mathrm{Cl}=1.33-75.65)$ and concurrent opportunistic infections (OR=8.69; $95 \% \mathrm{Cl}=1.45-52.22)$ were independently associated with case fatality. Blood lactate $>7$ $\mathrm{mmol} / \mathrm{l}$ showed a sensitivity of $84 \%$ for fatality with a specificity of $60 \%$ whereas bicarbonate $<12 \mathrm{mmol} / \mathrm{l}$ showed a better specificity (85\%) but a poorer sensitivity (42\%). Bicarbonate $<18 \mathrm{mmol} / \mathrm{l}$ appears to be as good as lactate $<7 \mathrm{mmol} / \mathrm{l}$ at predicting death
\end{abstract}


(sensitivity $90 \%$; specificity $54 \%$ ).

Conclusions: Our data suggest that a blood lactate $>7 \mathrm{mmol} / \mathrm{l}$ and blood bicarbonate $<18$ $\mathrm{mmol} / \mathrm{l}$ appear to predict death and might help clinicians in selecting patients who may benefit from more intense monitoring. 


\section{Introduction}

Lactic acidosis ( $\mathrm{LA})$ and severe hyperlactataemia $(\mathrm{HL})$ are infrequent but serious adverse drug reactions attributed to dideoxynucleosides. In well-resourced countries the incidence of HL/LA has decreased substantially over time, mainly because of changes in anti-retroviral therapy (ART) prescription patterns (1). However, the expanding access to ART in resource-limited regions has caused an important rise in the reported number of adverse reactions attributable to dideoxynucleosides $(2 ; 3)$. Incidence rates of HL/LA in South Africa have been reported as ranging from 10-19 cases per 1000 person-years on ART $(2 ; 4 ; 5)$ versus $0.8-8.7$ cases per 1000 person-years on ART in well-resourced countries (6). This apparent higher incidence of HL/LA in resource-limited countries might mainly be because stavudine (d4T) is often part of the first line combination therapy available in most countries. However, previously reported risk factors for HL/LA such as female gender and advanced HIV-induced immunosuppression are also more frequent in resource-limited settings $(3 ; 7)$.

Another factor which may explain in part the differences in incidence of HL/LA between studies is the lack of a universally accepted case definition for hyperlactataemic conditions in HIV-infected patients. Most case definitions proposed combine the presence of symptoms along with abnormal blood lactate levels to make a diagnosis (810)..

Although previous case-series and observational studies have shown fatality rates ranging between 15 to $60 \%(11-14)$, little is known about specific risk factors for fatality among patients with $\mathrm{HL} / \mathrm{LA}$. Observational studies have found blood lactate levels $>10$ $\mathrm{mmol} / \mathrm{l}$ and low bicarbonate to be associated with fatal outcome in patients with $\mathrm{LA} / \mathrm{HL}$ $(5 ; 13 ; 15)$.

Previously, in a large multinational case-control study we examined the risk factors for HL/LA. No analyses of the risk factors associated with mortality were performed (16). The aim of this study was to identify factors associated with a fatal outcome in the same study population.

\section{Participants and methods}

All participants who met the criteria for HL/LA in our multinational case-control study to identify risk factors for these complications in HIV-infected adults exposed to ART (16) were included in this retrospective cohort analysis. In the parent study severe hyperlactataemia $(\mathrm{HL})$ was defined as confirmed blood lactate $>5 \mathrm{mmol} / \mathrm{l}$, and lactic acidosis (LA) as blood $\mathrm{pH}<7.35$, bicarbonate $<20 \mathrm{mmol} / \mathrm{l}$ and lactate above normal range. Arterial gases, $\mathrm{pH}$ and bicarbonate were not measured in all patients with $\mathrm{HL}$.

The aim of the present analysis was to identify factors associated with fatality by comparing patients that died as a consequence of the event to patients who survived it. Demographics, clinical data on HIV infection, full ART exposure history, and acid-base 
balance and blood lactate laboratory values at the time of event diagnosis were recorded. Information on previous or concurrent ART-induced adverse reaction was also collected. Body mass index was not included in the analysis because data on height of most patients was not available.

Statistical analysis was performed using Stata version 10.1 (StataCorp LP, College Station, Texas, USA). Quantitative variables were summarised as medians and compared using the Mann-Whitney test. Categorical variables were presented as proportions and compared using Fisher's exact test. A logistic regression model to identify factors associated with fatality was built including those factors found significant $(\mathrm{P}<0.05)$ in the univariate analysis. Exact logistic regression was also used to deal with zero cells in the analysis when required (17). Logistic regression was used because of its good statistical. Sensitivity and specificity of different variables as predictor of death were compared. Receiver operating characteristic (ROC) curves were also used to examine the specificity and sensitivity at different thresholds of the measure. We would consider a variable as good predictor of death if its sensitivity is not lower than $80 \%$ and the specificity is $>50 \%$.

Ethical approval was obtained from all relevant ethics committees, including the Multicentre Research Ethics Committee of London. Written informed consent was obtained from study participants when requested by the relevant ethics committee.

\section{Results}

A total of 110 patients were included (49 with LA), of which 19 died $(17 \%)$ as a consequence of the event a median 8 days (Interquartile range -IQR- 3 to 16) after diagnosis. However, 16 out of the 19 patients who died had LA, so the case fatality rate among acidotic patients was $33 \%$ (16/49 cases). There was no association between either age, gender or ethnic background and death (Table 1). The median age of those who died was 41.3 years (IQR=37.8-49.2) and 42.8 years (IQR=35.9-53.8) for non-fatal patients $(P=0.737)$. There was no significant difference in the median CD4 cell count at the time of the diagnosis of the event in fatal versus non-fatal patients (188 cells $/ \mathrm{mm}^{3}(\mathrm{IQR}=89-370)$ and 253 cells $/ \mathrm{mm}^{3}(\mathrm{IQR}=144-360)$, respectively $(\mathrm{P}=0.242)$.

The median blood lactate at the time of diagnosis was $8.3 \mathrm{mmol} / \mathrm{I}(\mathrm{IQR}=7.2-13.1)$ for fatal cases and $6.4 \mathrm{mmol} / \mathrm{I}$ (IQR $5.4-7.8)$ for those who survived the event $(P<0.001)$. Patients who died with LA had a median lactate of $8.6 \mathrm{mmol} / \mathrm{l}(\mathrm{IQR}=7.2-13.8)$ whereas the three patients who died with $\mathrm{HL}$ had lactate values of $7.6,8.1$ and $11.4 \mathrm{mmol} / \mathrm{l}$. All these fatal $\mathrm{HL}$ patients also had low bicarbonate levels $(17-18 \mathrm{mmol} / \mathrm{l})$ but arterial blood $\mathrm{pH}$ was not measured. There were seven patients with LA who had lactate readings $<5$ $\mathrm{mmol} / \mathrm{l}$ at the time of diagnosis but lactate ranged between 5.6 and $20.3 \mathrm{mmol} / \mathrm{l}$ in those who died.

The median blood bicarbonate was significantly lower in patients who died (median 12 $\mathrm{mmol} / \mathrm{l} ; \quad \mathrm{QQR}=8.2-17$ ) compared to those who survived (median $18.9 \mathrm{mmol} / \mathrm{l}$; 
IQR=14.7-22.2) $(P<0.001)$. Blood lactate levels were monitored routinely as part of normal patient care in five of the 19 participating centres. The frequency of case fatality was not different in patients enrolled in centres where lactate was routinely measured $(7 / 36 ; 19 \%)$ compared to those in centres where it was not $(12 / 74 ; 16 \%)(P=0.789)$. Arterial blood $\mathrm{pH}$ was reported in 78 patients, 16 of whom died as consequence of the event $(21 \%)$. The median $\mathrm{pH}$ for fatal patients was $7.23(95 \% \mathrm{Cl}=7.11-7.31)$ whereas it was $7.35(95 \% \mathrm{Cl}=7.30-7.41)$ for non-fatal patients $(\mathrm{P}<0.001)$. Because arterial blood $\mathrm{pH}$ was not reported in a significant number of cases with $\mathrm{HL}$, it was not included in the multivariate model.

Most of the patients were receiving dideoxynucleoside-based ART at the time of the event. However, the proportion of patients who died on dideoxynucleosides $(12 / 19 ; 63 \%)$ was somewhat lower than the proportion of patients with non-fatal episodes on such drugs $(78 / 91 ; 86 \%)(P=0.043)$. Of the seven fatal patients who were not receiving dideoxynucleosides at the time of the event three ceased d4T four to seven weeks before the event, and four were receiving zidovudine/lamivudine (AZT/3TC)-based combinations and had never been exposed to dideoxynucleosides in the past. Most patients had gastro-intestinal (64\%) or constitutional symptoms $(57 \%)$ although no symptoms were reported in 10 patients $(9 \%)$. These asymptomatic patients had a median blood lactate of $5.8 \mathrm{mmol} / \mathrm{l}$ (range 5.1-7.3).

A sensitivity analysis using different threshold values for blood lactate as a dichotomous variable was conducted. Fitting the same model adjusted by age, concurrent opportunistic infections and current CD4 cell count, but varying the blood lactate threshold, a value of $7 \mathrm{mmol} / /$ resulted in the highest model likelihood (Table 2). ROC curves were constructed to assess the appropriateness of different thresholds of blood lactate or bicarbonate to construct binary predictors of death. There was no difference between the area under the curve (AUC) calculated for these variables. Levels of lactate ranging from 7.27 to $8.1 \mathrm{mmol} / \mathrm{l}$ as well as levels of bicarbonate ranging between 11 and $14 \mathrm{mmol} / \mathrm{l}$ appear to be good choices for cut-off in predicting death.

The model presented in table 3 shows a significant and independent association between lactate levels $7-10 \mathrm{mmol} / \mathrm{l}$ and fatality when compared to with $<7 \mathrm{mmol} / \mathrm{l}$ (OR=6.27; $95 \% \mathrm{Cl}=1.13-34.93)$. In addition, bicarbonate levels $<12 \mathrm{mmol} / \mathrm{l}$ showed an OR for death of $10.02(95 \% \mathrm{Cl}=1.33-75.65)$. There was some evidence of an increased death rate for bicarbonate $12-18 \mathrm{mmol} / \mathrm{l}(\mathrm{OR}=5.82 ; 95 \% \mathrm{Cl}=0.76-44.89)$. A sensitivity analysis was performed including only those individuals initially diagnosed with LA. All the variables found to be independently associated with fatality in the main analysis showed similar effects, both in terms of the magnitude and the direction of it. Among patients with LA, blood lactate 7-10 mmol (OR=6.24; $95 \% \mathrm{Cl}=0.78-49.61)$ and concurrent $\mathrm{OI}(\mathrm{OR}=5.68 ; 95 \% \mathrm{Cl}=0.74-43.69)$ appeared to be somehow associated with fatality. The effect of blood bicarbonate is less clear as, by definition, all patients had low bicarbonate at entry (median $11.95 \mathrm{mmol} / \mathrm{l}-\mathrm{IQR}=8.2-13.95-$ and $14.7 \mathrm{mmol} / \mathrm{l}$ $-I Q R=11.0-13.95$ - for fatal and non-fatal patients respectively). Similarly, no differences were seen in the direction of the association between any of the variables analysed and death when the analysis was restricted to patients from centres where lactate was 
routinely measured compared to those in centres where it was not (data not shown).

No symptom-free patient was acidotic or died, so absence of symptoms perfectly predicted survival. No association was found between the presence of any specific symptom and fatality. When the analysis was limited to symptomatic patients there was no change on the magnitude of the association between factors independently associated with death in the general model (data not shown). To explore the association between the presence of symptoms and death an exact logistic regression model was fitted (17). After adjusting by blood levels of lactate and bicarbonate, concurrent OI, CD4 cell count and age, the estimated association between symptoms and fatal outcome was inconclusive (OR $0.39 ; 95 \% \mathrm{Cl} 0.03$ - Infinity) because our study included too few asymptomatic patients (Table 4).

As shown on table 5 , the specificity of a model combining blood lactate $>7 \mathrm{mmol} / \mathrm{l}$ and bicarbonate $<12 \mathrm{mmol} / \mathrm{l}$ was $90 \%$ to predict fatality, although its sensitivity was $37 \%$. Blood lactate $>7 \mathrm{mmol} / \mathrm{l}$ showed a specificity of $60 \%$ but with a sensitivity of $84 \%$. Similarly, bicarbonate $<18 \mathrm{mmol} / \mathrm{l}$ showed a very high sensitivity $(90 \%)$ with a specificity similar to the figure calculated for lactate $>7 \mathrm{mmol} / \mathrm{l}(54 \%)$. On the contrary, the sensitivity of blood bicarbonate $<12 \mathrm{mmol} / \mathrm{l}$ was $42 \%$.

\section{Discussion}

Our study showed an overall fatality rate of $17 \%$ but, in patients with demonstrated LA, the rate was $33 \%$. This was similar to the $33 \%$ reported in a Spanish case-series and a retrospective cohort study in Soweto, South Africa, where seven of the 23 patients with LA died $(30 \%)(2 ; 13)$. Slightly lower rates have been reported in recent studies in Uganda and Cape Town, South Africa where five of 24 cases (21\%) and 11 of 73 cases $(15 \%)$ of LA died, respectively $(14 ; 18)$.

Two small European cohort studies of symptomatic HL showed that only those who eventually developed LA died $(19 ; 20)$. It has been suggested that $\mathrm{HL}$ may progress to LA if the offending drug is not discontinued $(9 ; 21)$. There is little evidence of $\mathrm{HL}$ leading to death unless acidosis is also present. None of the 44 cases of symptomatic $\mathrm{HL}$ included in a South African study died (2). In our study, the exact cause of death of the three patients with HL who died within two weeks after diagnosis was not recorded and therefore, we cannot exclude the possibility of other conditions contributing to the outcome. However, some patients in the HL group had blood lactate levels $>10 \mathrm{mmol} / \mathrm{l}$, which have been proposed as suggestive of acidosis (8). Therefore, some of the $\mathrm{HL}$ cases in whom blood $\mathrm{pH}$ was not measured may have had acidosis at the time of diagnosis.

Most reports of HL/LA in HIV-infected adults include only patients with suggestive symptoms but our study shows that patients with confirmed $\mathrm{HL}$ (blood lactate $>5 \mathrm{mmol} / \mathrm{l}$ ) can be asymptomatic or have symptoms mild enough to not be reported. In contrast, in a prospective cohort study John et al. found that all patients (5/349) who ever had a blood 
lactate $>5 \mathrm{mmol} / \mathrm{l}$ were clearly symptomatic (22). It has been suggested that asymptomatic HL may be due to spurious results from an inappropriate blood collection technique (23). However, it is unlikely that incorrect management of blood samples would produce consistent blood lactate levels $>5 \mathrm{mmol} / \mathrm{l}$. Nevertheless, because of the retrospective nature of this study, it is not possible to exclude the possibility of mild symptoms not being reported and or not being recorded in patient records.

Two previous studies have found lactate levels $>10 \mathrm{mmol} / \mathrm{l}$ as independently associated with death in patients with HL/LA $(13 ; 15)$. Our study included a higher number of fatalities than those previously reported and this provides greater power to assess the association between lactate and fatality. In our study blood lactate $>7 \mathrm{mmol} / \mathrm{l}$ was independently associated with death. Although, the lactic acidemia definition (8) showed a sensitivity of $100 \%(95 \% \mathrm{Cl} 82-100)$ for fatality its specificity was quite poor as $94 \%$ of non-fatal cases also had lactate $>5 \mathrm{mmol} / \mathrm{l}$. The sensitivity of lactate $>7 \mathrm{mmol} / \mathrm{l}$ was $84 \%$ but had a better specificity than the lactic acidemia definition (60\%). Adding bicarbonate $<12 \mathrm{mmol} / \mathrm{l}$ to lactate $>7 \mathrm{mmol} / \mathrm{l}$ increased its specificity to $90 \%$ but decreased its sensitivity from 90 to $40 \%$. Compared with the lactic acidemia definition, a combined definition based on blood lactate $(>7 \mathrm{mmol} / \mathrm{l})$ and bicarbonate $(<12 \mathrm{mmol} / \mathrm{l})$ as well as blood lactate $>7 \mathrm{mmol} / \mathrm{l}$ alone showed a better specificity for fatality (Table 5). Although most patients with HL/LA would recover after stopping exposure to the offending drugs, those with more severe episodes (i.e. those more likely to die) may benefit from more intense monitoring and additional interventions. Given the cost implications of intense follow-up and management for severe cases, a definition with the highest possible specificity would be ideal because it would reduce the number of false positives to a minimum. In that context, blood lactate $>7 \mathrm{mmol} / \mathrm{l}$ appeared to be a good predictor for fatality with high sensitivity and $60 \%$ specificity.

Stead et al., with 12 fatal cases in 89 cases in a South African retrospective cohort analysis, reported a significant association between low blood bicarbonate levels and death (5). In our study, after adjusting for other variables and potential confounders, the association between blood bicarbonate $<12 \mathrm{mmol} / \mathrm{l}$ and fatality was evident $(\mathrm{OR}=10.02$; $95 \% \mathrm{Cl}=1.33-75.65)$ when compared to those patients with bicarbonate levels $>18$ $\mathrm{mmol} / \mathrm{l}$. However, according to our results bicarbonate $<12 \mathrm{mmol} / \mathrm{l}$ may be a weak predictor for fatality on its own because of its poor sensitivity. Nevertheless, based on the calculated sensitivity and specificity for fatality ( $90 \%$ and $54 \%$ respectively), it appears that bicarbonate $<18 \mathrm{mmol} / \mathrm{l}$ may be as good as lactate $>7 \mathrm{mmol} / \mathrm{l}$ in predicting death. Furthermore, there was some evidence suggesting a possible association between bicarbonate ranging between 12 and18 mmol/l and fatality $(\mathrm{OR}=5.82 ; 95 \% \mathrm{Cl}=0.76$ 44.89 ) in the multivariate analysis.

In this study, concurrent $\mathrm{OI}$ were independently associated with fatal outcome. No association between fatality and markers of immunosuppression has been reported in previous studies. However, it has also been suggested that acute bacterial infections may induce LA in patients with high baseline blood lactate levels (21). As we did not record the precise cause of death we cannot exclude the possibility that concurrent infections played an important role in inducing LA leading to death in patients with 
previously compensated HL.

Although a number of studies have suggested an increased risk for HL/LA in non-white populations compared to white ones $(2 ; 4 ; 16 ; 24)$ we found no association between ethnic background and death. Similarly, fatality rates reported in African studies are not higher than those found in Europe $(2 ; 4 ; 13 ; 14)$. Therefore, one could assume that even if some ethnic groups may be at higher risk for $\mathrm{HL} / \mathrm{LA}$ when exposed to dideoxynucleosides, the outcome of their event is not necessarily worse than for white Europeans.

Most of the proposed classifications for blood lactate disorders in HIV-infected patients have used a threshold of $10 \mathrm{mmol} / \mathrm{l}$ to either make a diagnosis of severe $\mathrm{HL}$ (10) or classify a case of "lactic acidemia" regardless of the presence of symptoms $(8 ; 25)$. However, in the light of results of our study, it may be pertinent to consider a different threshold value, as patients with blood lactate $>7 \mathrm{mmol} / \mathrm{l}$ might be at a significant risk of dying. Although we have found asymptomatic patients with confirmed blood lactate $>5$ $\mathrm{mmol} / \mathrm{l}$, our data cannot be used to assess accurately the association between the presence of symptoms and fatality as none of the asymptomatic patients died and only $9 \%$ of the included patients were symptoms free. However, the association between lactate or bicarbonate levels and death appeared to remain at the same level predicted by the logistic regression model even after adjusting for the presence of symptoms in the exact logistic regression model (Table 4).

Using specific threshold values of blood lactate and/or bicarbonate levels would require regular monitoring of blood samples. A targeted approach might be appropriate i.e. in those individuals particularly at risk for HL/LA such as female patients, obese or overweight individuals, those with advanced HIV-induced immunosuppression, elderly patients and probably, those from non-white ethnic origin who are receiving dideoxynucleoside-based ART $(1 ; 2 ; 5 ; 16)$. Point-of-care blood lactate analysers have been successfully used in resource-limited settings to monitor patients on dideoxynucleoside-based therapies (26;27). In addition, in some middle-income countries standard bicarbonate is measured in patients with symptoms suggestive of $\mathrm{HL}(5)$.

Our study has some limitations. Patients were mostly from well resourced countries and so our results may be limited in their generalisability to resourced limited settings where the dideoxynucleosides (a stavudine and didanosine) are still widely used. However, our cases were diagnosed between 1997 and 2003 when dideoxynucleosides were frequently used in well resourced countries, the fatality rates reported by African investigators do not differ from rates reported in European studies and ethnic origin was not associated with fatality in our analysis. Patients were diagnosed with HL/LA and followed-up in different centres which had diverse policies, therefore, the availability of data was not uniform across the study population. Blood lactate was not routinely monitored in all participant centres; therefore some patients may have been tested for lactate because of the presence of symptoms, exposure to dideoxynucleosides or presence of another medical condition. However, we could not find any major difference between patients routinely tested for lactate and those who were not except for a stronger association between fatality and concurrent $\mathrm{OI}$ in patients not routinely tested for 
lactate. We did not collect data on cause of death, therefore we cannot exclude the contribution of other factors to the outcome. Finally, patients exposed to dideoxynucleosides tend to develop HL/LA within few months, so long-term exposure to ART on the cohorts where patients were extracted from may impact HL/LA incidence rate. However, because patients were identified retrospectively with non limitation on calendar period, the age of the cohort should have no major impact on incidence. Our study could not assess the effect of BMI on fatality.

In summary, patients with confirmed severe hyperlactataemia can be asymptomatic. In addition, blood bicarbonate $<12 \mathrm{mmol} / \mathrm{l}$, lactate $>7 \mathrm{mmol} / \mathrm{l}$ and concurrent Ol appeared to be associated with death in patients with $\mathrm{HL} / \mathrm{LA}$. Blood lactate $>7 \mathrm{mmol} / \mathrm{l}$ and perhaps bicarbonate $<18 \mathrm{mmol} / \mathrm{l}$ can predict death and may help to identify patients who may benefit from more intense monitoring. 
Acknowledgements: The study group wish to thank Joanna Turner, Claudia Ochoa, Sophie Herbert, Lars Mathiesen, Jan Gerstoft, Mooka Busi, Luuk Gras, Sima Zaheri, Shula Grivell, Teresa García-Benayas, Erika Gremlich, Sundhiya Mandalia, Emma MacFarlane, Anele Waters, Lisa Heald, and Glen Curran for their support in retrieving patients' information.

Members of the Lactic Acidosis International Study Group: Argentina: Pedro Cahn (Fundación Huesped, Buenos Aires); Australia: Andrew Carr (St Vincent's Hospital, Sydney); Jennifer Hoy (Alfred Hospital, Melbourne); Denmark: Signe Westring Worm, Jens Lundgren (Hvidovre Hospital, Copenhagen); Ireland: Fiona Mulcahy (St James' Hospital, Dublin), Paddy Mallon, William Powderly (University College Dublin); The Netherlands: Peter Reiss (Academic Medical Center, Amsterdam); Spain: Esteban Martínez (Hospital Clinic, Barcelona), Vincent Soriano (Hospital Carlos III, Madrid); Switzerland: Rainer Weber (University Hospital, Zurich); UK: Alejandro Arenas-Pinto, lan Weller, Andrew Copas (University College London), Alison Grant, Krishnan Bhaskaran (London School of Hygiene \& Tropical Medicine), Simon Edwards (Camden Primary Care NHS Trust), David Dunn (Medical Research Council, London), Chris Taylor (King's College Hospital, London), Alec Bonington (North Manchester General Hospital, Manchester), Jonathan Ainsworth (North Middlesex Hospital, London), Martin Fisher (Brighton General Hospital, Brighton), Moses Kapembwa (Northwick Hospital, London), Graeme Moyle (Chelsea \& Westminster Hospital, London); US: Turner Overton (Washington University, St Louis); Venezuela: Julio Castro, Alejandro Arenas-Pinto (Universidad Central de Venezuela, Caracas).

Sponsorship: The original study was funded by an educational grant from Bristol-Myers Squibb. AAP was partially funded by the Consejo de Desarrollo Científico y Humanístico, Universidad Central de Venezuela. 


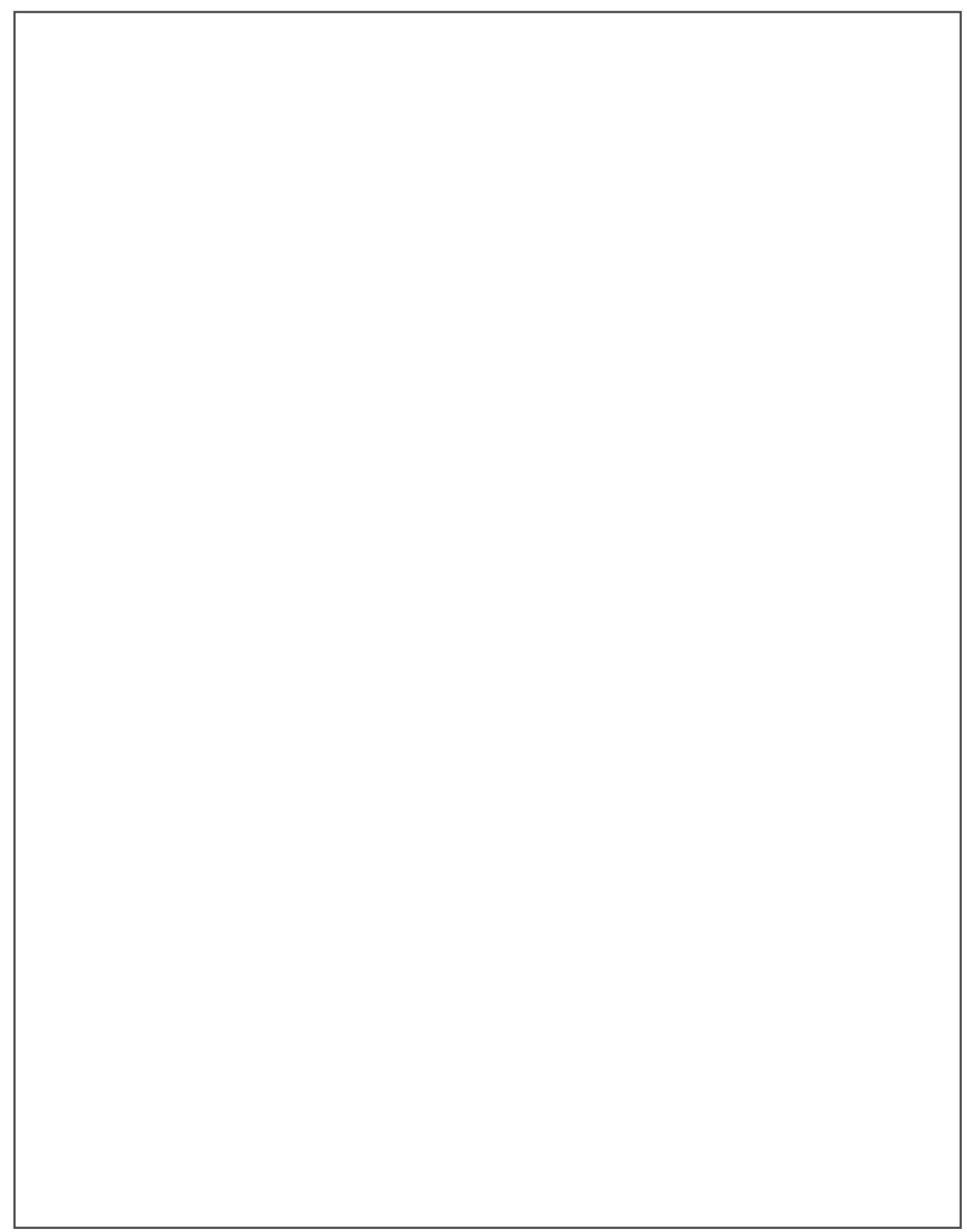




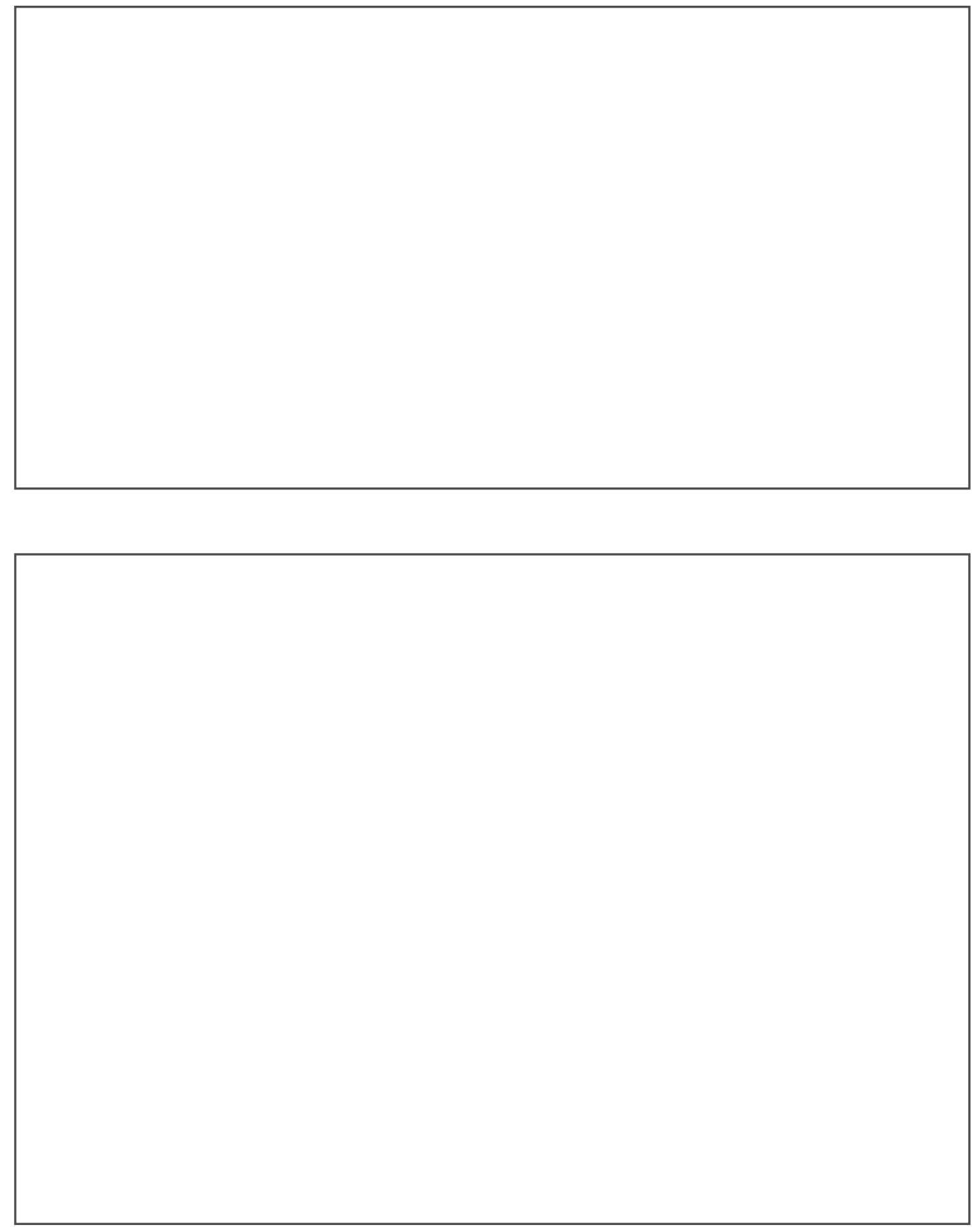



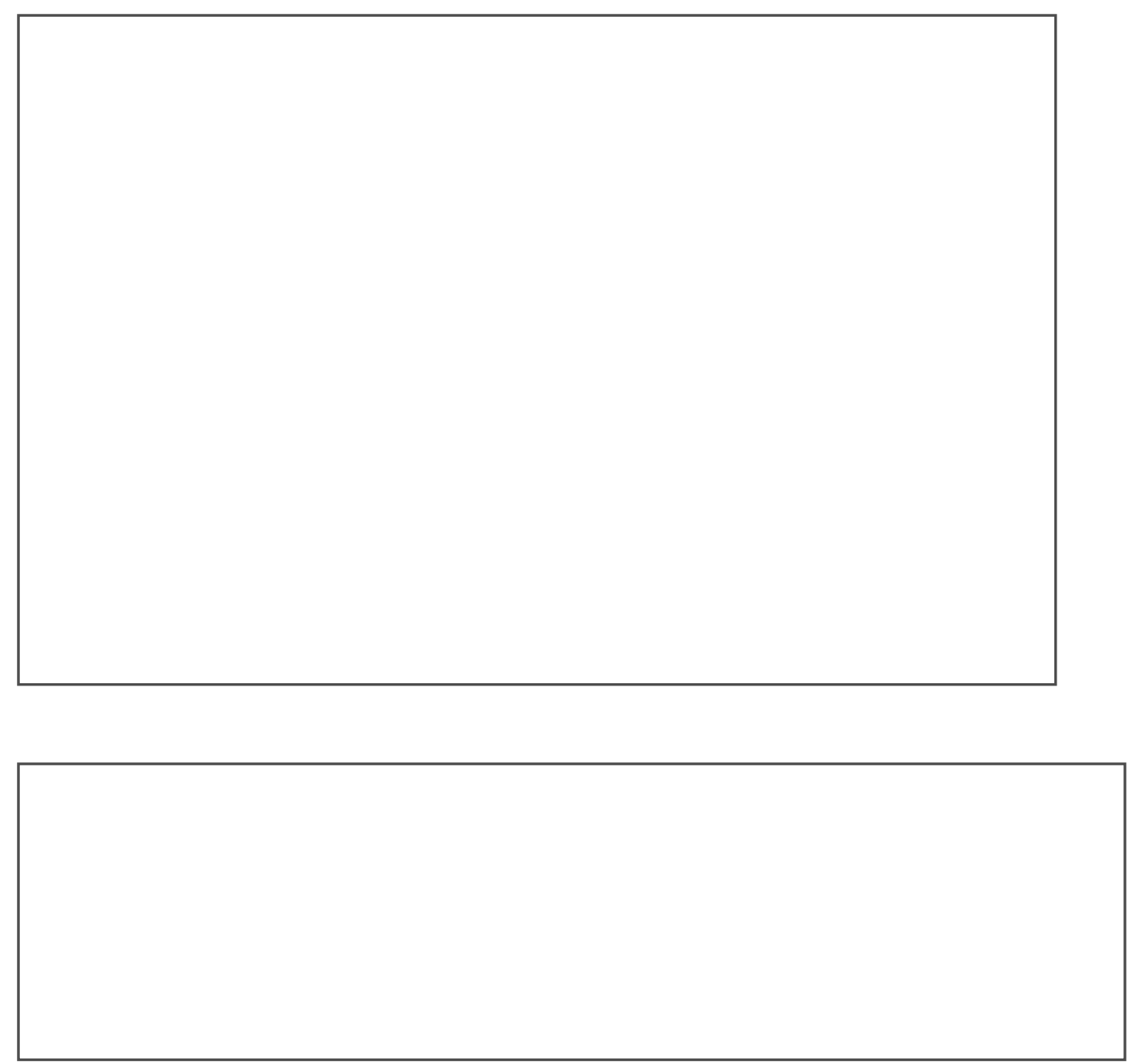
References

1. Imhof A, Ledergerber B, Gunthard HF et al. Risk factors for and outcome of hyperlactatemia in HIV-infected persons: Is there a need for routine lactate monitoring? Clinical Infectious Diseases 2005; 41:721-728.

2. Bolhaar MG, Karstaedt AS A high incidence of lactic acidosis and symptomatic hyperlactatemia in women receiving highly active antiretroviral therapy in Soweto, South Africa. Clin Infect Dis 2007; 45:254-260.

3. Boulle A, Orrel C, Kaplan R et al. Substitutions due to antiretroviral toxicity or contraindication in the first 3 years of antiretroviral therapy in a large South African cohort. Antivir Ther 2007; 12:753-760.

4. Geddes R, Knight S, Moosa MY et al. A high incidence of nucleoside reverse transcriptase inhibitor (NRTI)-induced lactic acidosis in HIV-infected patients in a South African context. S Afr Med J 2006; 96:722-724.

5. Stead D, Osler M, Boulle A et al. Severe hyperlactataemia complicating stavudine first-line antiretroviral therapy in South Africa. Antivir Ther 2008; 13:937943.

6. Calza L, Manfredi R, Chiodo F Hyperlactataemia and lactic acidosis in HIVinfected patients receiving antiretroviral therapy. Clin Nutr 2005; 24:5-15.

7. Calmy A, Pinoges L, Szumilin E et al. Generic fixed-dose combination antiretroviral treatment in resource-poor settings: multicentric observational cohort. Aids 2006; 20:1163-1169.

8. Carr A Lactic acidemia in infection with human immunodeficiency virus. Clin Infect Dis 2003; 36:S96-S100.

9. Powderly WG Long-term exposure to lifelong therapies. Journal of Acquired Immune Deficiency Syndromes 2002; 29:S28-S40.

10. John M, Mallal S Hyperlactatemia syndromes in people with HIV infection. Curr Opin Infect Dis 2002; 15:23-29.

11. Arenas-Pinto A, Grant AD, Edwards $S$ et al. Lactic acidosis in HIV infected patients: a systematic review of published cases. Sexually Transmitted Infections 2003; 79:340-344.

12. Megarbane B, Brivet F, Guerin JM et al. Lactic acidosis and multiorgan failure secondary to antiretroviral treatments in HIV-infected patients. Presse Medicale 1999; 28:2257-2264.

13. Falco V, Rodriguez D, Ribera E et al. Severe nucleoside-associated lactic acidosis in human immunodeficiency virus-infected patients: report of 12 cases and 
review of the literature. Clin Infect Dis 2002; 34:838-846.

14. Songa PM, Castelnuovo B, Mugasha EB et al. Symptomatic hyperlactatemia associated with nucleoside analogue reverse-transcriptase inhibitor use in HIV-infected patients: a report of 24 cases in a resource-limited setting (Uganda). Clin Infect Dis 2007; 45:514-517.

15. Manosuthi W, Prasithsirikul W, Chumpathat $\mathrm{N}$ et al. Risk factors for mortality in symptomatic hyperlactatemia among HIV-infected patients receiving antiretroviral therapy in a resource-limited setting. Int J Infect Dis 2008; 12:582-586.

16. Arenas-Pinto, A., Grant, A. Dunn, D., Carr, A., Reiss, P., Edwards, S., Worm, S.W., Overton, T., Martinez, E., Hoy, J., Copas, A., Cahn, P., Weber, R., Bhaskaran, K., Weller, I. and the Lactic Acidosis International Study Group. Risk factors for lactic acidosis and severe hyperlactataemia in HIV-1-infected adults exposed to antiretroviral therapy. Aids 2007; 21:2455-2464.

17. Cox DR, Snell EJ Analysis of Binary Data. Boca Raton: Chapman \& Hall/CRC; 1989.

18. Osler M, Stead D, Rebe K et al. Risk factors for and clinical characteristics of severe hyperlactataemia in patients receiving antiretroviral therapy: a casecontrol study. HIV Med 2010; 11:121-129.

19. Hocqueloux L, Alberti C, Feugeas JP et al. Prevalence, risk factors and outcome of hyperlactataemia in HIV-infected patients. HIV Med 2003; 4:18-23.

20. Gerard Y, Maulin L, Yazdanpanah Y et al. Symptomatic hyperlactataemia: an emerging complication of antiretroviral therapy. Aids 2000; 14:2723-2730.

21. Moyle GJ, Datta D, Mandalia S et al. Hyperlactataemia and lactic acidosis during antiretroviral therapy: relevance, reproducibility and possible risk factors. Aids 2002; 16:1341-1349.

22. John M, Moore CB, James IR et al. Chronic hyperlactatemia in HIVinfected patients taking antiretroviral therapy. Aids 2001; 15:717-723.

23. Wohl DA, Pilcher CD, Evans $S$ et al. Absence of sustained hyperlactatemia in HIV-infected patients with risk factors for mitochondrial toxicity. Jaids-Journal of Acquired Immune Deficiency Syndromes 2004; 35:274-278.

24. Gerard Y, Yazdanpanah Y, Ajana F et al. Use of stavudine is associated with a high risk of severe hyperlactataemia in black women. Antiviral Therapy 10 , L42-L43. 2005.

25. Schambelan M, Benson CA, Carr A et al. Management of metabolic complications associated with antiretroviral therapy for HIV-1 infection: recommendations of an International AIDS Society-USA panel. J Acquir Immune Defic Syndr 2002; 31:257-275. 
26. Ivers LC, Mukherjee JS Point of care testing for antiretroviral therapyrelated lactic acidosis in resource-poor settings. Aids 2006; 20:779-780.

27. Mathee $\mathrm{S}$, Abrahams $\mathrm{M}$, Jackson $\mathrm{N}$ et al. Point of care lactate testing is an effective measure in supporting the WHO first-line regimen in settings with a high incidence of stavudine-related toxicity. XVI International AIDS Conference. [Toronto, Canada]. 2006. 